\title{
Herança do formato do fruto em tomateiro do grupo cereja
}

\author{
Gabriel Mascarenhas Maciel; Ernani Clarete da Silva \\ UNIFENAS, Setor de Olericultura e Experimentação, C. Postal 23, 37130-000 Alfenas-MG, clarsil@bol.com.br
}

\section{RESUMO}

O formato dos frutos do tomateiro é resultado da ação de diversos loci gênicos que podem atuar de diversas formas: isoladamente, com efeitos pleiotrópicos ou interagindo entre si ou com genes responsáveis pelo peso do fruto. Em função disto, o estudo da herança desta característica, importante para o melhoramento da espécie, torna-se complexa e de difícil execução. Este trabalho foi desenvolvido no Setor de Olericultura e Experimentação da Universidade José do Rosário Vellano (UNIFENAS), de Julho/2003 a Março/2005 com o objetivo de determinar a herança da forma do fruto em tomateiro do grupo cereja. Foram utilizados dois genótipos selvagens e contrastantes quanto à forma do fruto: fruto comprido (FC) e fruto redondo (FR). Cruzamentos recíprocos e retrocruzamentos foram efetuados sendo a forma do fruto, avaliada nas gerações oriundas desses cruzamentos. Todas as plantas da geração $F_{1}$ produziram frutos redondos. Em $\mathrm{F}_{2}, 111$ plantas produziram frutos redondos e 47 plantas produziram frutos compridos. No retrocruzamento $\left(\mathrm{F}_{1} \times \mathrm{FC}\right)$ 47 plantas produziram frutos redondos e 42 plantas produziram frutos compridos. Estes resultados, analisados pelo teste de $x^{2}$ confirmaram segregação mendeliana 3:1 e 1:1 respectivamente. Concluiuse que o formato dos frutos estudados tem herança monogênica. $\mathrm{O}$ alelo que condiciona a forma redonda do fruto tem dominância completa sobre o alelo que confere a forma alongada com possível atuação do locus sun.

Palavras-chave: Lycopersicon esculentum Mill, melhoramento, genética.

\section{ABSTRACT}

\section{Inheritance of fruit shape in cherry tomato group}

The tomato fruit shape is a result of action of various gene loci that can act in several ways: alone, with pleiotropic effects or interacting with each other or with genes responsible for the fruit weight. According to this, the study of the inheritance of this characteristic, very important for the improvement of the species, is complex and difficult to implement. This work was carried out at the Horticultural and Experimentation Section of José do Rosário Vellano University, during the period of July 2003 through March, 2005 with the objective to determine the fruit shape of the cherry tomato plant. Two wild genotype contrasting tomato plants were utilised with the fruit shape: long fruit shape (LF) and round fruit shape (RF). Reciprocal crosses and backcross were realised and the fruit shape was evaluated in the generations origininated from these crosses. All plants of the $F_{1}$ generation produced round shape fruit. In the $\mathrm{F}_{2}$ generation, 111 plants produced round fruit shape and 47 plants produced long fruit shape. On the backcross generation $\left(\mathrm{F}_{1} \mathrm{x}\right.$ LF) 47 plants produced round fruit shape and 42 plants produced long fruit shape. These results when analysed by chi square, confirmed Mendelian segregation 3:1 and 1:1 respectively. It was concluded that the studied fruit shape has monogenic inheritance. The allele that determines fruit round shape has complete dominance over the allele that determines elongated shape fruit with possible action of the sun locus.

Keywords: Lycopersicon esculentum Mill, breeding, genetics.

\section{(Recebido para publicação em 9 de janeiro de 2007; aceito em 30 de setembro de 2008) (Received in August 15, 2008; accepted in October 31, 2008)}

$P^{2}$ ra efeito de identificação, o tomateiro (Lycopersicon esculentum Mill) foi classificado em grupos, sendo atualmente considerados seis grupos: Santa Cruz, Industrial, Salada, Saladinha, Saladete e Cereja (Alvarenga, 2000).

Segundo Azevedo Filho \& Melo (2001), o tomateiro do tipo cereja foi introduzido no Brasil através das fezes de pássaros migratórios e pelos imigrantes italianos que chegaram ao país no final do século XIX. As plantas são de crescimento indeterminado com número de frutos/penca variando de 15 a 50, de forma redonda ou comprida, pesando entre 10 e 30 gramas, de coloração vermelho-brilhante (Diez Niclos, 1995; Filgueira, 2000; Postali et al, 2004). Este tipo de tomate tem mercado diferenciado e melhores preços e, ultimamente, tem sido usado para ornamentação de pratos e "couvert" (Alvarenga, 2000). O tomateiro do grupo cereja, caracterizado pela produção de frutos pequenos, difere completamente dos objetivos da produção dos demais grupos onde se preconiza frutos graúdos como característica desejável (Silva et al., 1997).

Tomateiros silvestres do tipo cereja apresentam crescimento espontâneo em qualquer tipo de solo e condições climáticas e têm as sementes disseminadas via fezes de pássaros (Azevedo Filho \& Melo, 2001). Provavelmente, devido a esta espontaneidade e ao não uso de agrotóxicos, as plantas sofreram ao longo dos anos uma pressão de seleção natural para rusticidade e tolerância às principais pragas e doenças. Tais características têm sido aproveitadas por produtores orgânicos no plantio comercial desta espécie (Azevedo Filho \& Melo, 2001). As plantas são vigorosas, de vegetação abundante, agressiva e apresentam frutos de coloração vermelha-intensa, com formas bem definidas e contrastantes, redondo ou comprido (Postali et al., 2004).

O estudo da herança de características de importância agronômica em vegetais é uma atividade de grande importância, cujos resultados são amplamente utilizados pelos fitomelhoristas. O conhecimento do número de genes envolvidos em determinado caráter, a sua localização no cromossomo, bem como a sua maneira de interagir, permitem construir mapas cromossômicos, determinar o critério e a intensidade da seleção, método de condução de população segregante, assim como determinar ideótipos de plantas com características 
desejáveis (Allard, 1971; Ramalho et al., 2000; Bueno et al., 2001). Embora poucas características de interesse econômico sigam a herança clássica ou mendeliana, o seu uso como ferramenta para a consecução de objetivos de melhoramento vegetal ainda é comum e pode ser significativamente mais eficiente quando associada às modernas técnicas de marcadores moleculares (Ferreira \& Grattapaglia, 1995), principalmente quando o melhoramento é assistido por estes marcadores.

Ramalho et al. (2000) relatam em livro, resultados de estudos da herança da forma do fruto em tomateiro onde foram obtidos resultados de herança monogênica com dominância completa da forma redonda sobre a forma alongada.

Segundo Tanksley (2004), os frutos originários de espécies domesticadas muitas vezes têm o seu tamanho expressivamente aumentado em relação ao normalmente encontrado nas espécies selvagens progenitoras. $\mathrm{O}$ autor ainda cita como exemplo o possível ancestral selvagem do tomate cultivado, Lycopersicon esculentum cv Cerasiforme, com dois lóculos e pesando apenas algumas gramas, em contraste a um simples fruto de tomate das variedades modernas que pode conter muitos lóculos e pesar até $1000 \mathrm{~g}$. Por outro lado a domesticação de espécies vegetais com conseqüente aumento no tamanho dos frutos, tem provocado expressiva variação na sua forma uma vez que, frutos de tomateiros selvagens e semi-selvagens são quase invariavelmente redondos enquanto que tomates cultivados vêm de uma ampla variedade de formas: redondo, oblongo, piriforme e em forma de torpedo (Tanksley, 2004). Os genomas de tomateiros cultivados contem menos de 5\% da variação genética de seus congêneres selvagens (Miller \& Tanksley, 1990). Em outras palavras, segundo Tanksley (2004), os tomateiros cultivados variam expressivamente em forma e tamanho dos frutos, mas têm pouca variação genética em qualquer outra parte de seu genoma sendo o contrário nas espécies selvagens. A explicação do aumento na variação da forma dos frutos do tomateiro é problemática e pode haver diver- sas explicações. Uma das explicações diz que a seleção para aumento no tamanho do fruto, pode ter levado à mudanças no seu formato atribuído a fenômenos de pleiotropia (Tanksley, 2004). Existem robustas evidências que apóiam esta hipótese no que diz respeito às mutações as quais têm provocado aumento no tamanho dos frutos por meio do aumento do número de carpelos / lóculos (Lippman \& Tanksley, 2001). Estes mesmos autores afirmam que, similarmente, mutações que afetam a forma do fruto podem ter grande efeito fenotípico em background de frutos pequenos versus frutos grandes. Correlação altamente significativa foi encontrada entre o tamanho do fruto e a forma do fruto sendo que, frutos maiores, mostraram formas mais extremas do que seus homólogos de frutos pequenos. Observa-se que o formato dos frutos do tomateiro é resultado da ação de diversos loci gênicos que podem atuar de diversas formas. Em função disto, o estudo da herança desta característica, importante para o melhoramento da espécie, torna-se complexa e de difícil execução. Por outro lado, estudos de herança da forma de frutos específicos para tomateiros silvestres do grupo cereja não foram encontrados na literatura. Assim, objetivo deste trabalho foi estudar a herança da forma redonda e comprida de frutos de tomateiro do grupo cereja em genótipos silvestres da espécie.

\section{MATERIAL E MÉTODOS}

O trabalho foi conduzido no município de Alfenas, sul de Minas Gerais, nas dependências da Universidade José do Rosário Vellano - UNIFENAS, Setor de Olericultura e Experimentação ( $21^{\circ} 14^{\prime} \mathrm{S} ; 45^{\circ} 00^{\prime} \mathrm{W}, 910 \mathrm{~m}$ de altitude) no período de janeiro de 2003 a fevereiro de 2005.

Foram utilizadas duas linhagens silvestres de tomateiro do grupo cereja (Figura 1), cujas sementes foram coletadas nos municípios de Lavras (MG) e Alfenas (MG). Estes genótipos têm sido conservados pelo setor de Olericultura e Experimentação da UNIFENAS e apresentam características bem definidas e contrastantes quan- to ao comprimento e ao diâmetro dos frutos. A linhagem coletada em Lavras (MG) tem frutos compridos, de coloração vermelha-intensa e ombros verdes. As plantas são vigorosas e agressivas, com brotações axilares e florais. As sementes da linhagem coletada em Alfenas (MG) produzem plantas vigorosas, cujos frutos são redondos e de coloração vermelha-intensa, sem ombro verde e com tamanho menor que os frutos compridos. Também produzem com abundância brotações nas axilas das folhas e nos ramos florais. Ambas as cultivares são de crescimento indeterminado.

A metodologia utilizada constou de cruzamentos biparentais recíprocos e retrocruzamentos da geração $F_{1}$ para $o$ genitor de fruto comprido e foi dividida em etapas distintas. Na primeira etapa foi avaliada a homozigose dos genitores e foram efetuados os cruzamentos biparentais. Sementes de ambos os genitores foram semeadas em casa-devegetação para a produção de mudas. Foram utilizadas bandejas de isopor de 128 células e substrato comercial misturado com palha de arroz carbonizada na proporção de 1:1 e 800 gramas de adubo formulado 4-14-8 para cada 40 litros da mistura (Frujuelle et al, 2003). Quando as mudas atingiram quatro folhas definitivas, foram transplantadas para a casa-de-vegetação. As plantas foram conduzidas com apenas uma haste e tutoradas verticalmente. Todos os tratos culturais e fitossanitários foram realizados de acordo com o preconizado para a cultura.

Para esta primeira etapa foram conduzidas 50 plantas de cada genitor, dispostas em espaçamento $1,5 \times 0,80 \mathrm{~m}$. Quando as plantas começaram a emitir os ramos florais foram selecionadas as três plantas mais sadias e vigorosas de cada genitor. O estado da planta é um bom indicativo de seu estado nutricional, o que, segundo Howlet (1936), tem influência na produção de pólen. Nos ramos florais (cacho) das plantas selecionadas, foram escolhidas antes da antese as três primeiras flores para a emasculação (Barrons \& Lucas, 1942). As flores não emasculadas foram todas eliminadas para evitar possível autofecundação e formação dos frutos. 
Esta operação foi realizada em ambos os genitores de maneira a permitir os cruzamentos recíprocos. Utilizando um vibrador manual, retirou-se pólen de flores completamente abertas em plantas de ambas as linhagens. Os grãos-de-pólen foram colocados em cápsulas de sílica-gel devidamente identificadas e utilizados para polinização de flores emasculadas no mesmo dia (Dempsey \& Boynton, 1962). As flores emasculadas que sofreram hibridização foram marcadas com lã vermelha. As sementes foram colhidas nos frutos maduros das flores marcadas. A homozigose dos genitores quanto à forma dos frutos foi avaliada observandose o formato dos frutos nas 50 plantas respectivas a cada genótipo parental. Todas as avaliações de formato dos frutos foram feitas visualmente considerando o diâmetro transversal e longitudinal dos frutos (Figura 1).

A segunda etapa consistiu na colheita e plantio das sementes $\mathrm{F}_{1}$ dos cruzamentos recíprocos. O plantio foi realizado, assim como na primeira etapa, também em casa-de-vegetação, juntamente com os genitores. Após obtenção de uma população com 100 plantas $\mathrm{F}_{1}$ (50 plantas de cada cruzamento) e 30 plantas de cada parental, o formato do fruto foi avaliado na população $F_{1}$, ao mesmo tempo em que retrocruzamentos de $\mathrm{F}_{1}$ para o parental de fruto comprido foram realizados. Todos os cuidados de condução da cultura e cruzamentos observados na etapa anterior foram observados também nesta etapa. Sementes $\mathrm{F}_{2}$ oriundas de autofecundação de $\mathrm{F}_{1}$ e sementes dos retrocruzamentos foram colhidas, constituindo assim material para a terceira etapa do trabalho.

$\mathrm{Na}$ terceira etapa, as sementes produzidas na etapa anterior foram utilizadas na produção de mudas, observando-se os mesmos procedimentos das etapas anteriores. Em duas casas-de-vegetação foram constituídas uma população de 158 plantas da geração $F_{2}$ (segregante) e 89 plantas oriundas de sementes do retrocruzamento. Nas populações $\mathrm{F}_{2}$ e de retrocruzamentos, as plantas foram contadas e separadas de acordo com o formato do fruto que produziram. Em seguida os dados foram submetidos ao teste de $\mathrm{c}^{2}$ de acordo com

Tabela 1. Número de plantas de tomate-cereja que apresentaram frutos de formato comprido ou redondo (number of cherry-tomato plants that showed tomato-fruit-shaped long or round). Alfenas, UNIFENAS, 2005.

\begin{tabular}{|c|c|c|c|c|c|c|}
\hline \multirow{3}{*}{ Fenótipos } & \multicolumn{6}{|c|}{ Gerações } \\
\hline & \multirow[b]{2}{*}{$P_{1}$} & \multirow[b]{2}{*}{$\mathbf{P}_{2}$} & \multicolumn{2}{|c|}{$\begin{array}{l}\text { Cruzamentos } \\
\text { recíprocos }\left(F_{1}\right)\end{array}$} & \multirow{2}{*}{$\begin{array}{c}\text { Cruzamento } \\
\text { teste } \\
\left(F_{1} \times F C\right)\end{array}$} & \multirow{2}{*}{$F_{2}$} \\
\hline & & & $P_{1} \times P_{2}$ & $\mathbf{P}_{2} \times \mathbf{P}_{1}$ & & \\
\hline Fruto comprido & 50 & & & & 42 & 47 \\
\hline Fruto redondo & - & 50 & 50 & 50 & 47 & 111 \\
\hline Total & 50 & 50 & 50 & 50 & 89 & 158 \\
\hline
\end{tabular}

a freqüência esperada e observada de frutos compridos e frutos redondos, tendo como hipótese uma segregação mendeliana 3:1, obtida para herança monogênica com dominância completa (Falconer, 1987; Ramalho et al, 2000).

\section{RESULTADOS E DISCUSSÃO}

Os genitores utilizados no cruzamento foram fenotipicamente homozigotos para a característica formato do fruto, uma vez que não foi observada segregação após as autofecundações (Tabela 1). Todos os frutos produzidos pela linhagem coletada em Lavras foram compridos, enquanto todos os frutos produzidos pela linhagem coletada em Alfenas foram redondos. Observou-se também dominância completa do fenótipo fruto redondo sobre fruto comprido, já que na geração $\mathrm{F}_{1}$ todas as plantas produziram frutos redondos, independente da direção do cruzamento (Tabela 1). Na geração $\mathrm{F}_{2}$, os valores absolutos indicaram uma segregação cuja proporção se aproximou de 3:1, uma vez que ocorreram 118 plantas com frutos redondos e 47 plantas com frutos compridos (Tabela 1). De modo semelhante, no cruzamentoteste realizado entre plantas $\mathrm{F}_{1}$ e o genitor de frutos compridos 42 plantas produziram frutos compridos e 47 plantas produziram frutos redondos, uma proporção próxima de 1:1. Quando aplicado o teste de $x^{2}$ os desvios entres as freqüências observadas e esperadas não foram significativos ( $\mathrm{p}<0,05)$, considerando a hipótese de segregação 3:1 ou seja, três frutos redondos para cada fruto comprido na geração $\mathrm{F}_{2}$.

Segundo Tanksley (2004) não existe uma completa separação entre loci que controlam o tamanho dos frutos e aqueles que controlam a forma dos mesmos. Entretanto, os loci fasciated (cromossomo 11) e locule-number (cromossomo 2), responsáveis pelo tamanho dos frutos, afetam também a forma, embora outros loci maiores ( $f w 1.1$, $f w 2.2$, fw3.1 e fw4.1) com a mesma função, exercem largamente seus efeitos no desenvolvimento dos frutos resultando em pequena mudança no seu formato. Da mesma forma, existem três loci maiores que modulam a forma dos frutos: ovate (cromossomo 2), sun (cromossomo 7) e fs8 (cromossomo 8) (Tanksley, 2004). Segregação de um locus gênico condicionando forma de pêra nos frutos foi relatada por pesquisadores na década de 1900 (Hendrick \& Boot, 1907; Price \& Drinkard, 1908). Durante este mesmo período outros pesquisadores relataram locus gênico similar causando forma oval nos frutos e que mais tarde foi demonstrado que estes genes provavelmente eram alélicos sendo este locus referenciado como ovate (Lindstrom 1928,1929). Bem mais tarde $\mathrm{Ku}$ et al. (1999) demonstraram que apenas este locus (ovate) poderia condicionar tanto a forma de pêra quanto a forma alongada do fruto indexando comprimento e diâmetro.

Análise de QTL de um cruzamento entre uma variedade de tomate Yellow Pear de frutos pequenos e de formato pêra e uma espécie selvagem, de frutos redondos (S. pimpinellifolium, LA 1589) revelou que frutos de formato pêra é largamente determinada por um outro QTL maior no cromossomo $2(\mathrm{Ku}$ et al, 1999). Tanksley \& Fulton (2007) observaram que este QTL aparentemente corresponde ao locus gênico ovate. $\mathrm{Na}$ formação dos frutos foram também observados, efeitos de alongamento da for- 
Tabela 2. Teste de $x^{2}$ da hipótese para herança monogênica da característica formato de fruto em tomate-cereja (chi square test the hypothesis for monogenic inheritance of the characteristic shape of fruit in cherry tomato). Alfenas, UNIFENAS, 2005.

\begin{tabular}{lccccccc}
\hline \multirow{2}{*}{ Fenótipos } & \multicolumn{3}{c}{ Geração $\mathbf{F}_{2}$} & & \multicolumn{3}{c}{ Cruzamento-teste } \\
\cline { 2 - 3 } & FO $^{1}$ & FE $^{1}$ & Desvio & & FO $^{1}$ & FE $^{2}$ & Desvio \\
\hline Fruto comprido & 47 & 39,5 & 7,5 & & 42 & 44,5 & $-2,5$ \\
Fruto redondo & 111 & 118,5 & $-7,5$ & & 47 & 44,5 & 2,5 \\
\hline Total & 158 & 158 & $X^{2}=1,90^{\text {ns }}$ & & 89 & 89,0 & $X^{2}=1,75^{\text {ns }}$ \\
\hline
\end{tabular}

${ }^{1} / \mathrm{FO}=$ frequiência observada (frequency observed) $;{ }^{2} / \mathrm{FE}=$ frequiência esperada (freuency expected)

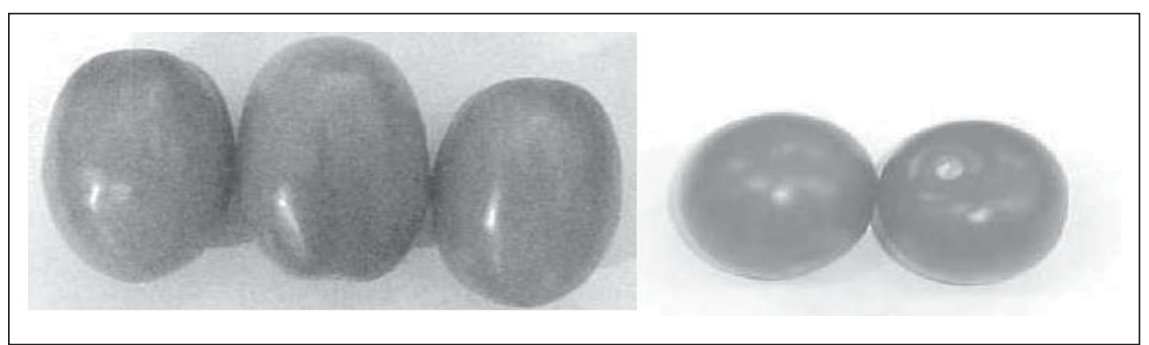

Figura 1. Frutos de linhagens silvestres de tomateiro do grupo cereja com formatos comprido e redondo (fruits round and elongated shape of wild strains of tomato plant of cherry tomato group). Alfenas, UNIFENAS, 2005.

ma que não se relacionava com uma mutação de ovate. Estudos revelaram a presença de um segundo locus maior no cromossomo 7 envolvido com a forma de frutos de tomate que foi denominado sun (Van der knaap \& Tanksley, 2001). Entretanto, estes dois loci diferem entre si em aspectos de importância genética, morfológica e de desenvolvimento. Uma destas diferenças é que sun causa o alongamento do fruto nas duas direções longitudinais mantendo uma simetria bilateral dos frutos enquanto que ovate resulta em um alongamento assimétrico do fruto onde o ápice do fruto é mais exagerado que a parte basal (Van der Knaap et al., 2002). Também, segundo estes mesmos autores, a forma de pêra dos frutos nunca foi relacionada com o gene sun.

Segundo Liu et al (2002) a mutação associada com uma mudança da forma do fruto de redondo para alongado ou pêra criou uma parada prematura no códon do segundo exon. Essa possível perda de função é consistente com o comportamento recessivo do alelo que condiciona fruto de formato alongado ou de formato pêra.

Portanto, é possível concluir que o formato dos frutos estudados tem herança monogênica. $\mathrm{O}$ alelo que condiciona a forma redonda do fruto tem dominância completa sobre o alelo que confere a forma alongada com possível atuação do locus sun.

\section{REFERÊNCIAS}

ALLARD RW. 1971. Princípios do melhoramento genético de plantas. São Paulo: Edgard Blucher Ltda, 381p.

ALVARENGA MAR. 2000. Cultura do tomateiro. Textos Acadêmicos. Lavras, UFLA, 91p.

AZEVEDO FILHO JA; MELO AMT. 2001. Avaliação de tomate silvestre do tipo cereja. In: CONGRESSO BRASILEIRO DE OLERICULTURA, 41 resumos... Brasília; ABH (CD-ROM)

BARRONS KC; LUCAS CE. 1942.The production of first - generation hybrid tomato seed for commercial planting. Proceedings of the American Society for Horticultural Science 40: 305-402.

BUENO LCS; MENDES ANG; CARVALHO SP. 2001. Melhoramento Genético de Plantas: princípios e procedimentos. Lavras: UFLA 282p.

DEMPSEY WH; BOYNTON JE. 1962. Effect of the time of the day on controlled pollinations. Report of the Tomato Genetics Cooperative 12: 23-24.

DIEZ NICLOS J. 1995. Tipos varietables. In: NUEZ F. (Coord.) El cultivo del tomate. Madrid: Mundi Prensa. p.93-129.

DORAIS M; GOSSEGIN A; PAPADOPOLOUS AP. 2001. Greenhouse tomato fruit quality. Horticulture Reviews 26: 239-306.

FALCONER DS. 1987. Introdução a genética quantitativa. Trad. de Martinho de Almeida e Silva e José Carlos Silva. Viçosa: UFV. 270 p.

FERREIRA ME; GRATTAPAGLIA D. 1995. Introdução ao uso de marcadores moleculares em análise genética. Brasília:EMBRAPACENARGEN .220p.
FILGUEIRA, FAR. 2000. Novo manual de olericultura Viçosa: UFV. 402p.

FRUJUELLE TM; SILVA EC; MACIEL GM. 2003. Avaliação de um retentor de água na composição de substratos para produção de mudas de tomate. In: CONGRESSO BRASILEIRO DE OLERICULTURA, 43. Resumos...Recife:ABH (CD-ROM)

GIORDANO LB; ARAGÃO FAS; BOITEUX LS. 2003. Melhoramento genético do tomateiro. Informe Agropecuário 24: 43-57.

HEDRICK UP; BOOTH NO. 1907. Mendelian characters in tomatoes. Proceedings of the American Society for Horticultural Science 5:19-24.

KU HM; DOGANLAR S; CHEN KY; TANKSLEY SD. 1999. The genetic basis of pear-shaped tomato fruit. Theoretical and Applied Genetics 9: 844-850.

LIPPMAN Z; TANKSLEY SD. 2001. Dissecting the genetic patway to extreme fruit size in tomato using a cross between the small-fruited wild species $L$ pimpinellifolium and $L$. esculentum, var. Giant Heirloom. Genectics 158: 413-422.

LINDSTRON EW. 1928. Linkage of size, shape and colors genes in Lycopersicum. Verh. 5th Int. Kong. Vererb. Ber. 2: 1031-1057.

LINDSTRON EW. 1929. Fruit-size and shape genes on the first chromosome of the tomato. Iowa Academy of Science 36: 189-190.

LIU J; Van ECK J; CONG BTANKSLEY SD. 2002. A new class of regulatory genes underlying the cause of pear-shaped tomato fruit. Proceeding of the National Academy of Sciences 99: 13302-13306.

MILLER JC; TANKSLEY SD. 1990. RFLP analisys of philogenetic relatioships and genetic variation in the genus Lycopersicon. Theoretical and Applied Genetics 80: 437-448.

POSTALI LGB; SILVA EC; MACIEL GM. 2004. Produção de híbridos comerciais de tomateiro do grupo cereja cultivados no sistema hidropônico com diferentes números de hastes. In: CONGRESSO BRASILEIRO DE OLERICULTURA, 44. Resumos... Campo Grande: ABH (CD-ROM).

PRICE HL; DRINKARD AW. 1908. Inheritance in tomato hybrids. Virginia Agricultural Experiment Station Bull 177: 15-53.

RAMALHO MAP; SANTOS JB; PINTO CABP. 2000. Genética na agropecuária. Lavras: UFLA. $472 \mathrm{p}$.

SILVA EC; ALVARENGA MAR; CARVALHO JG. 1997. Produção e podridão apical do tomateiro (Lycopersicon esculentum Mill) podado e adensado sob influência da adubação nitrogenada e potássica. Ciência $e$ Agrotecnologia 21: p.324-333.

TANKSLEY SD. 2004. The genetic, developmental, and molecular basis of fruit size and shape variation in tomato The plant cell 16: S181-S189.

TANKSLEY SD; FULTON TM. 2007. Dissecting quantitative trait variation: examples from the tomato. Euphytica 154: 365-370.

Van der KNAAP E; LIPPMAN ZD; TANKSLEY SD. 2002. Extremely elongated tomato fruit controlled by four quantitative trait loci with epistatic interactions. Theoretical and Applied Genetic 104: 241-247.

Van der KNAAP E; TANKSLEY SD. 2001. Identification and characterization of a novel locus controlling early fruit development in tomato. Theoretical and Applied Genetic 103: 353-358. 